\title{
An Analysis Of Teacher Effectiveness Related To Technology Implementation In Texas Secondary Schools
}

Andrea Kuyatt, Bishop CISD, USA

Glenda Holland, Texas A\&M University-Commerce, USA

Don Jones, Texas A\&M University-Kingsville, USA

\begin{abstract}
In the age of accountability, schools are struggling to reach every student to bring them up to the high academic standards mandated by the federal and state governments. Teachers must use research-based strategies to help decrease the learning gap for all students (Kimmelman, 2006). While the use of technology to engage students is a popular tool, how teachers use the technology available to them may determine the effectiveness of the lesson for the students. State assessment scores measure student success and the effectiveness of the instruction they are receiving. Technology may be a means to increase that effectiveness to take more students to a deeper level of understanding.

An analysis of variance was used to evaluate the data from surveys on the ways technology was used in the classroom and the level of implementation of use in the classroom. There was a statistical difference on test scores for teachers who used technology in the classroom and those who did not. The study showed the teachers who implemented technology in their classrooms had lower scores than teacher who did not. The ability to implement technology in student lessons and the use of content standards with technology may change student engagement in the classroom (Harris \& Hofer, 2011). This information could be significant in helping administrators determine successful instructional strategies for their schools.
\end{abstract}

Keywords: Accountability; Technology; Teacher Effectiveness; Student Success

\section{INTRODUCTION}

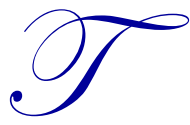

he ability of the teacher to use technology in a way that will improve student learning and participation in educational activities has been the basis for studies conducted in recent years (Overbay, Mollette, \& Vasu, 2011). The introduction of the No Child Left Behind (NCLB) Act brought technology to the forefront with the requirements of Title II, Part D, enhancing education through technology and increasing pressure in the accountability rating for all schools (Texas Education Agency, 2012). According to Goe (2007), effective teaching may be measured by many factors such as qualifications and experience, high expectations, classroom environment and the ability to motivate students. While research is conducted to narrow the focus of effective teaching strategies many legislators rely more on evidence such as state and federal teaching credentials that are obtained through testing to prove competence than the measurement of the ability of the teacher to implement quality instruction (Stumbo \& McWalters, 2010). Goe (2007) states, "there is not a clear consensus that any of the measured characteristics have a clear impact on student achievement" (p. 32). With so many schools under sanctions for student performance and administrators who strive to meet the federal requirements to keep their schools as top performing, administrators and school boards turn to student assessment scores as a measurement of teacher effectiveness. 
The current educational system is driven by high stakes accountability. Schools are continually searching for effective solutions that will eliminate educational barriers and lead all students to success. Texas Education Agency (TEA) is the state monitoring division that helps guide programs in public education (Texas Education Agency, 2012). TEA provides schools with monitoring and assessment results for Texas public schools based on student performance, student groups, and financial divisions. The student assessment reports posted to the TEA website include Adequate Yearly Progress Report (AYP), which is a federal report; the Academic Excellence Indicator System report (AEIS), the state version of AYP; and the Performance-Based Monitoring Analysis System (PBMAS) report which measures student accessibility and performance of subgroups (Texas Education Agency, 2012). Each of these reports indicates overall student performance data yet fall short of assisting teachers and schools in understanding the individual impact of teacher practices that may influence the testing outcomes.

Administrators look to teacher quality to achieve these goals and search for methods on how to turn ineffective teachers into successful partners. Historically, teachers who have many years of teaching experience have been the cornerstones of school leadership. These teachers have mastered classroom management, curriculum sequencing, and instructional practices. However, with new technology and youth who are proficient enough to master multi-tasking and technological media, teachers who are more adept at the new technology age are fast becoming personnel who are in high demand with school districts. Watching a teenager play video games or text is an example of an engaged student. Teachers who take advantage of the student preferred mode of instructional delivery will engage and reach the students of today (Rosen, 2011).

Current research identifies many aspects of teacher effectiveness. Studies on instructional practices, curriculum alignment and school culture have been identified as contributing to teacher effectiveness (The Gates Foundation, 2012). Unfortunately, the structure of our teacher effectiveness system has not examined the degree in which teachers implement technology and to the capacity in which teachers take advantage of the instructional and learning tools they have at their disposal.

As schools search for ways to meet the demands of No Child Left Behind's academic standards, they turn to teacher effectiveness criteria to determine how to help meet the needs of students. Researchers have differing opinions on specific teacher qualities and their effects on student performance (The Gates Foundation, 2012). Few studies have been conducted to determine if teachers are using technology as a learning tool as opposed to a teaching tool. Using technology as an instructional tool in the classroom may aid students in their motivation to learn increasingly difficult material. Today's schools require teachers to maintain an orderly environment conducive to learning, we expect them to effectively help students learn a multitude of information, and now we also expect them to be proficient in all technological resources to engage students academically. These increasing demands will call for continual support from the school district in areas such as technology resources, professional development, and time for technology mastery. Schools that recognize exemplary teachers based on just one or two of these requirements may be missing important linkage for an overall exemplary program.

The purpose of this causal comparative study was to determine if, first, teachers who are successful, as measured by the state assessment, are using technology in the English language arts and social studies classrooms at the secondary level in Region 2 public schools in South Texas. A second purpose of the study was to determine if there is a difference in student performance as measured by technology and the level of classroom implementation. The study was guided by the following questions: 1) Is there a difference in the technology implementation for teachers whose students score high on state assessment and those whose students score low on state assessment? and 2) What are teachers' levels of implementation of their instructional methods that improve student learning?

The No Child Left Behind Act, signed into law by President George W. Bush in 2002, required states to increase their accountability, use research-based strategies, obtain highly qualified teachers, and narrow achievement gaps for all students (Kimmelman, 2006). The increasingly high standards that students must meet on state and federal accountability weigh heavily on the shoulders of school systems. States, such as Texas, are continually assessing students on higher and higher standards to meet the measures set by legislators. To successfully attain this mark, schools must continually assess, monitor, and use the tools which bring them the greatest success. 
This study could be significant for school leaders in helping them decipher instructional strategies that are meaningful and have promising results. Administrators would be able to use the study to evaluate groups of teachers and instructional practices they routinely use to enhance instruction and motivate students to perform well in the classroom and on assessments. They will be able to analyze the impact of technology in the classroom, the way in which the technology is implemented, and the professional development needed to support the classroom technology.

\section{METHOD}

This study was a non-experimental quantitative study. Surveys would determine trends, attitudes or opinions of groups. Creswell (2009) identified the survey design method procedures as one in which the researches "generalize or make claims about the population" (p.145). The survey provided quality research from the quantitative methods which was synthesized into a well-rounded, in-depth study (Creswell, 2009).

As stated in the research questions, two main ideas need to be addressed. First was the quantitative data of the student proficiency on the state assessment scores. These data were collected through annual federal and state reports on student academic performance on the STAAR test. Second, the data were disaggregated to develop two populations of teachers - first, a group that was successful, by state standards, with their students on the STAAR test and proficient - defined by the researcher as a teacher scoring above 1600 in English language arts and 3700 in social studies. The second group included those teachers who were not successful on the STAAR test, according to the state standards, or scored below 1600 in English language arts and 3700 in social studies. These teachers were then given a quantitative survey using a Likert scale to assess the level of technology implementation that occurred in their classroom.

The study was conducted with middle schools in Region 2 of South Texas. The results of this study were based on student test scores from the State of Texas Assessment of Academic Readiness (STAAR) and surveys from the teachers who taught those students during the 2011-2012 school year. The researcher used an analysis of variance (ANOVA) to test the null hypothesis of no significant differences in the use of technology in the classroom of students who are proficient on the STAAR exam and those who are non-proficient.

\section{Instrumentation}

Two instruments were used to conduct the research. The first was the STAAR assessment which is the state assessment developed by the Pearson Corporation and which is aligned to the state standards. All Texas public school students are required to participate in the assessment.

The second instrument was a technology survey for teachers which was developed by Vannatta and O'Bannon and previously given to teachers who participated in the "Goals 2000 Pre-service Technology Infusion Project". The survey evaluates the proficiency of teachers to use technology and the manner in which the technology is applied in the classroom.

The Teacher Technology Integration survey consisted of four sections: 1) Risk Taking and Comfort with Technology, 2) Technology Access, 3) Teacher Administrative and Instructional Use, and 4) Configuration of Student Use. The first two sections were not used in the study. The third part of the survey measured how the teachers use technology in the classroom, and the last section measured the teachers' perceptions of how students use technology in their classroom. This survey is based on a Likert scale of 1-4, with 4 having the highest value. The options for choice were $1=$ None, $2=$ Rarely (once or twice a month), $3=$ Moderately (several times per semester), and 4=High (Almost weekly per semester).

A teacher's total score for the survey was derived from multiple questions on the survey and the Likert scale score was added for each of the teachers. This score was divided by the proficient and non-proficient teachers. The totals of the proficient teachers' scores were added together and divided by the number of proficient teachers. The non-proficient teachers' scores were then added together and divided by the number of non-proficient teachers. 


\section{Reliability And Validity}

The survey also evaluates the capacity of the students' use of computer and media in the classroom (MuirHerzig, 2004). According to Muir-Herzig, this survey has been used numerous times with various teacher samples and has generated reliability coefficients (Cronback's alpha) ranging from $\mathrm{r}=0.8185$ to $\mathrm{r}=0.9265$ ".

\section{Population And Sample}

This study focused on a number of proficient teachers $(n=23)$ and who had students who were successful on the STAAR state assessment. The study additionally included a number of non-proficient teachers $(n=23)$ whose students were not successful on the STAAR as measured by state standards. The teachers were from varied demographic backgrounds located in Region 2 in South Texas and were selected from various size school districts and communities. All teachers included in the survey taught at public schools.

\section{Procedures}

The study began with the identification of schools in Region 2 area. The researcher collected English language arts (ELA) and social studies scores from Region 2 Education Service Center schools from the STAAR assessment that was administered in the spring of 2012. Scores from the STAAR assessment are available online through the Texas Education Agency website. Schools were contacted to retrieve the names of teachers in the subject areas of ELA and social studies for survey data collection. School names and contact information were accessible through the Education Service Center, Region 2 website. The researcher contacted the individual teachers through the school mail and and systems. Teachers were mailed a survey to collect data to assess their technology knowledge and methods of implementing technology in the classroom and surveys were mailed back to the researcher within two weeks. Teacher data were confidential; the teacher's names remained anonymous.

Creswell (2009) stated that data analysis for a survey study consisted of compiling the reports of procedures gathered from the quantitative data and expounding on the development of depth of information through the analysis procedure. While the two types of data will be synthesized together, two individual reports will also be produced.

\section{RESULTS}

The purpose of this study was to analyze whether there was a difference in the use of technology for teachers who had proficient scores on STAAR tests and in the technology use of those who did not have proficient scores in STAAR tests. This study took place at Texas public middle schools located in Region 2 of South Texas and utilized student data from the State of Texas Assessment of Academic Readiness (STAAR) scores from the 2011-2012 school year. The Teacher Technology Survey was utilized to collect from teachers who were teaching students linked to the STAAR scores.

The researcher utilized two sections of the survey that related to both teacher and student use of technology to investigate the significant relationship between test scores and teachers who use technology in the classroom. Part one measured whether teachers were using technology for management purposes, such as attendance or grades. The second section of the survey measured how the students used technology for learning in the classroom. Statistics for each group were run individually and then as a combined group. In using the combined group, the researcher was able to add the effect size statistic for each of the dependent variables.

Forty-six teachers participated in the technology survey. Of the 46, 23 scored proficient and 23 scored nonproficient in their STAAR scores. The mean for the proficient scores was computed by taking the average of all of the proficient scores and dividing by twenty-three.

In Table 1, respondents answered questions related to teacher use of technology in the classroom. The nonproficient teachers' mean was 52.39 with a standard deviation of 7.191 , while the proficient teachers' mean was 47.26 with a standard deviation of 6.390 . 
The mean for the non-proficient scores was computed by taking the average of all of the non-proficient scores and dividing by 23 . The Likert scale was used with a range of 21 to 96 on the possible scoring ability, with 36 being the median. The results of the two independent groups are reported in Tables 1 and 2.

Table 1: Descriptive Statistics For Teacher Use

\begin{tabular}{lccc}
\hline \multicolumn{1}{c}{ Test } & Mean & Standard Deviation & N \\
\hline Non-proficient & 52.39 & 7.191 & 23 \\
Proficient & 47.26 & 6.390 & 23 \\
Total & 49.83 & 7.209 & 46 \\
\hline
\end{tabular}

In Table 2, results were based on teachers' answers for student use of technology in the classroom. Nonproficient teachers had a mean of 53.22 with a standard deviation of 15.765 and proficient teachers had a mean of 40.96 with a standard deviation of 13.646 .

Table 2: Descriptive Statistics For Student Use

\begin{tabular}{lccc}
\hline \multicolumn{1}{c}{ Test } & Mean & Standard Deviation & N \\
\hline Non-proficient & 53.22 & 15.765 & 23 \\
Proficient & 40.96 & 13.646 & 23 \\
Total & 47.09 & 15.842 & 46 \\
\hline
\end{tabular}

Table 3 is the combined scores for both teachers' and students' technology use in the classroom. The nonproficient teachers' mean was 105.61 with a standard deviation of 21.339 and the proficient teachers' mean was 88.22 with a standard deviation of 18.839 .

Test of Between-Subject Effects is reported in Table 3.

Table 3: Descriptive Statistics For Total Technology Use From The Teacher Technology Survey

\begin{tabular}{lccc}
\hline \multicolumn{1}{c}{ Test } & Mean & Standard Deviation & N \\
\hline Non-proficient & 105.61 & 21.339 & 23 \\
Proficient & 88.22 & 18.839 & 23 \\
Total & 96.91 & 21.758 & 46 \\
\hline
\end{tabular}

After running the ANOVA for the total technology use, the Levene's test was run to ensure that the assumption of homogeneity was met. Levene's Test of Equality of Error Variances is reported in Table 4.

Table 4: Dependent Variable: Total Technology Use-Teachers And Students

\begin{tabular}{ccccc}
\hline F & df1 & df2 & Sig. \\
\hline .034 & 1 & 44 & .855 \\
\hline
\end{tabular}

Overall, there is a significant difference, as noted in Table 5, in the use of technology in the classroom and the students' test scores $[F(1,44)=8.59, p<.01]$. There was a significant difference in the STAAR scores and the level of implementation of technology in the classroom. Students whose teacher did not use technology were more successful on their STAAR exam, as measured by the Teacher Technology Survey, than those whose teacher did use technology.

Table 5: Dependent Variable: Overall Technology Use-Teachers and Students

\begin{tabular}{lcccccc}
\hline \multicolumn{1}{c}{ Source } & $\begin{array}{c}\text { Type III Sum } \\
\text { of Squares }\end{array}$ & df & Mean Square & F & Sig. & $\begin{array}{c}\text { Partial Eta } \\
\text { Squared }\end{array}$ \\
\hline Corrected Model & $3475.261^{\mathrm{a}}$ & 1 & 3478.261 & 8.586 & .005 & .163 \\
Intercept & 432038.348 & 1 & 432038.348 & 10663439 & .000 & .005 \\
Proficiency & 3478.261 & 1 & 3478.348 & 8.586 & & 163 \\
Error & 17825.391 & 44 & 405.123 & & & \\
Total & 453342.000 & 46 & & & \\
Corrected & 21303.652 & 45 & & & & \\
\hline${ }^{\mathrm{a}} \mathrm{R}$ Squared $=.163$ (Adjusted R Squared $\left.=.144\right)$ & & & & \\
\hline
\end{tabular}


The results of the proficiency test and 95\% Confidence Level are shown in Table 6.

Table 6: Proficiency And Confidence Measurement

\begin{tabular}{lcccc}
\hline \multicolumn{1}{c}{ Proficiency } & Mean & Standard error & \multicolumn{2}{c}{ 95\% confidence level } \\
\hline & & & Lower Bound & Upper Bound \\
\cline { 3 - 4 } Non-proficient & 105.609 & 4.197 & 97.150 & 114.067 \\
Proficient & 88.217 & 4.197 & 79.759 & 96.676 \\
\hline
\end{tabular}

\section{RESULTS SUMMARY}

A one-way Analysis of variance was conducted to evaluate the difference between proficiency on STAAR testing in English language arts and social studies and the teachers' level of implementation of technology. The independent variable, the teacher's class STAAR score, included two levels: proficient and non-proficient. The dependent variable was the level of implementation of technology in the classroom. The ANOVA was significant, $F(1,44)=8.59, p=.005$. The strength of the relationship between test score proficiency and teacher technology use in the classroom, as assessed by $\eta^{2}$, was strong, with the test scores accounting for $16 \%$ of the variance of the dependent variable (Green \& Salkind, 2011).

Follow-up tests were conducted to evaluate pairwise differences among the means. Because the variance of the two groups ranged from 354.95 to 455.40 , an assumption that the variances were homogeneous was not made and the Levene's test of Equality of Error Variances was used. There was a significant difference in the means between the proficient and non-proficient scores. The group that received proficient scores showed a lower teacher use of technology. The group with non-proficient scores showed a higher teacher use of technology. The 95\% confidence intervals for the pairwise differences, as well as the means and standard deviations for the two groups, are reported in Table 4 (Green \& Salkind, 2011).

On teacher use of technology, teachers of students who were not proficient on their STAAR testing had a higher mean score $(M=52.39, \mathrm{SD}=7.19)$ than those whose students were proficient $(\mathrm{M}=47.26, \mathrm{SD}=6.39)$. Additionally, the same pattern was found on the student use of technology, non-proficient students $(M=53.22$, SD $=15.77)$, and for proficient students $(\mathrm{M}=40.96$, SD 13.65). The combined total for the two groups mirrored the individual test for the categories non-proficient $(M=105.61, S D=21.34)$ and proficient $(M=96.91, S D=18.84)$. The F-value suggested that there was a significant difference in the scores. Therefore, there was a significant difference in the relationship of STAAR scores and teachers who use technology in the classroom.

\section{DISCUSSION}

Identification of effective educational practices to enhance student learning continues to be a difficult task (Goe, 2007). As schools continue to implement required technology standards and look for ways to implement more technology, they must still be cognizant of the proficiency level of their students as they must master the state objectives. In this study, the use of technology by the teacher or student did not enhance their proficiency level on the Texas state assessment. The researcher did not survey students of the classroom which were measured. Additionally, teachers who completed the survey potentially have a skewed view on the level of implementation of their technology usage. It is difficult to determine the accuracy of the survey which was completed by the teachers.

It appears that it is not enough to use technology by teachers or students but to understand and identify factors that would be able to contribute to student learning. Monitoring the use of technology for content areas or for technology standards may have an impact on student scores as well (Miranda \& Russell, 2011). School administrators need to closely evaluate the technology use and progress on their campuses and evaluate the implementation of technology and how it relates to student test scores. The researcher identifies the need for more in-depth research on this subject before changing school technology programs. 


\section{CONCLUSION}

Schools must continually find ways to meet the standards of No Child Left Behind and determine effective strategies to engage students in their education. The focus of many studies to improve student achievement has turned to technology usage and teacher effectiveness. Current research identifies many aspects of teacher effectiveness. Studies on instructional practices, curriculum alignment, and school culture have been identified as contributing to teacher effectiveness (The Gates Foundation, 2012). However, the results of this study indicated that there was a problem with technology usage in the classroom with regard to state assessment scores, such as STAAR. The results indicated that teachers who used technology in the classroom would score lower on state assessments than teachers who did not use technology in the classroom.

Several variables could have affected these outcomes regarding the use of technology and assessment scores. Variables that could affect the final outcome of the study would be the fidelity and integrity of teachers who are completing the survey. The sample size of the study group could be another affected variable. Finally, the difference of opinions from students and teachers on the manner in which technology is used can possibly differ.

\section{RECOMMENDATIONS FOR PRACTITIONERS}

The findings of the study question the use of technology in instructional improvement. The researcher offers the following recommendations: 1) Schools should evaluate current instructional practices regarding the implementation of technology in the classroom, 2) Administrators could document technology methods and state assessment scores for correlational activities, and 3) Schools can provide strategies that will develop technology standards and provide purpose to the use of technology for learning.

\section{AUTHOR INFORMATION}

Andrea Kuyatt currently serves as Director for Career and Technology Education and Federal Programs and she previously served as a campus administrator and educational consultant. Interests include curriculum development, school culture, and program effectiveness. Email: akuyatt@bishopcisd.net.

Glenda Holland served in administrative and teaching roles at the university level for the past 25 years. Research interests include program improvement and recruitment, mentoring, and retention of educators. Email: glenda.holland@ tamuc.edu.

Don Jones is a former superintendent and high school principal. For the past six years, he has served as an assistant professor in the Department of Educational Leadership and Counseling at Texas A\&M University-Kingsville. His research interests include school finance, leadership ethics, school board and leadership team development, and leadership theory and innovations for public schools. Email: Don.Jones@tamuk.edu.

\section{REFERENCES}

1. Creswell, J. W. (2009). Research design: Qualitative, quantitative, and mixed methods approaches (3rd ed.). Thousand Oaks, CA: SAGE Publications, Inc.

2. The Gates Foundation. (2012, January 20). Empowering effective teachers. Retrieved January 23, 2012 from http://www.gatesfoundation.org/unitedstates/documents/empowering-effective-teachers-empoweringstrategy.pdf

3. Green, S. B., \& Salking, N. J. (2011). Using SPSS for Windows and Macintosh: Analyzing and understanding data (06 ed.). Upper Saddle River, NJ: Pearson Education.

4. Goe, L. (2007, October). The link between teacher quality and student outcomes: A research synthesis. Retrieved February 2, 2012 from http://www.tqsource.org/publications/LinkBetweenTQandStudentOutcomes.pdf.

5. Journal of Research on Technology in Education, 43(3), 211-229.

6. Kimmelman, P. L. (2006). Implementing NCLB. Thousand Oaks, CA: Corwin Press.

7. Miranda, H., \& Russell, M. (2011). Predictors of teacher-directed student use of technology in elementary 
classrooms: A multilevel SEM approach using data from the USEIT study. Retrieved April, 22, 1013 from http://www.ncbi.nlm.nih.gov/pmc/articles/PMC3257493/.

8. Muir-Herzig, R. G. (2004). Technology and its impact in the classroom. Computers \& Education, 42, 111131.

9. $\quad$ A technology plan that works. Educational Leadership, 68(5), 56-59.

10. Rosen, L. D. (2011). Teaching the iGeneration. Educational Leadership, 68(5), 17-21.

11. Stumbo, C., \& McWalters, P. (2010). Measuring effectiveness: What will it take? Educational Leadership, 64(4), 10-15.

12. Texas Education Agency. (2012). Texas Education Agency. Retrieved February 2, 2012 from http://www.tea.state.tx.us/index2.aspx?id=150. 